\title{
Proximal Esophageal Granular Cell Tumor: A Case Report and Review of Literature
}

\author{
Lakis Remi, Matar Rasha and Hallal Mahmoud* \\ Department of Gastroenterology and Hepatology, Alzahraa Hospital University Medical Center, Lebanon
}

Submission: September 16, 2019; Published: September 25, 2019

*Corresponding author: Hallal Mahmoud, Department of Gastroenterology and Hepatology, Al Zahraa Hospital University Medical Center (Zhumc), Beirut, Lebanon

Abstract

Granular cell tumors (GCTs) are uncommon soft tissue tumors that originate from Schwann cells, they are usually benign (approximately 0.5\%-2\% have been reported as malignant). They occur predominantly in the oral cavity, skin, and breast tissues. Gastrointestinal GCTs are very rare, accounting for only $8 \%$ of all GCTs, most of which are located in the esophagus. Endoscopic ultrasound is essential in providing the depth of tumor invasion. However, the definitive diagnosis requires histological confirmation of the lesion. Here, we report a case of 22-yearold female who presented with a complaint of dysphagia of few months duration and was diagnosed with the granular cell tumor (GCT) in the Proximal Esophagus after esophagogastroduodenoscopy (EGD) and endoscopic ultrasound (EUS), which was removed in block by endoscopic mucosal resection (EMR).

Keywords: Granular cell tumor; Dysphagia; Esophagus; Esophagogastroduodenoscopy; Endoscopic ultrasound; Proximal esophagus; Oral cavity; Skin; Breast tissues; Breast; Respiratory tract; Granular cell tumor; Cytoplasmic lysosomes; Subcutaneous tissue; Biopsies; Odynophagia; Regurgitation; Reflux; Dyspepsia

Abbreviations: GCT: Granular Cell Tumor; EGD: Esophagogastroduodenoscopy; EUS: Endoscopic Ultrasound; EMR: Endoscopic Mucosal Resection; FNA: Fine Needle Aspiration; ESD: Endoscopic Submucosal Dissection

\section{Introduction}

Granular cell tumors (GCTs) were initially described by Arbikoss of back to 1926 when they were known as Abrikoss of tumors or granular cell myoblastoma [1,2]. They were known later as granular cell tumors from the fact that an accumulation of cytoplasmic lysosomes imparts the tumor with a granular appearance. Most commonly, they can be found at oral cavity, skin and subcutaneous tissue, breast, and respiratory tract. GCTs rarely affect the gastrointestinal tract. They are infrequent lesions, originating from Schwann cells and constituted $1 \%$ of all esophageal tumors [3]. This is the case of a healthy 22-year-old female who presented with dysphagia and was diagnosed with proximal esophageal granular cell tumor on esophagogastroduodenoscopy (EGD) and endoscopic ultrasound (EUS). Biopsies were conducted and the pathology confirmed the diagnosis. Although Hundreds of cases were reported in the literature about esophageal GCTs, the proximal location and younger age were less commonly found, making this case unique.

\section{Case Report}

A 22-year-old nonsmoker female with negative past medical and surgical history presented for dysphagia of few months duration. She had dysphagia mainly to solids with globus sensation and frequent throat clearing without odynophagia, regurgitation, reflux, dyspepsia or weight loss. No previous medications were taken. Family history was noncontributory. Her Physical exam was non-significant. Her CBCD did not show anemia or any other abnormalities. Esophagogastroscopy was performed showing $1 \mathrm{~cm}$ yellowish submucosal lesion $16 \mathrm{~cm}$ from the incisors just below the upper esophageal sphincter. Patient was referred for endoscopic ultrasound (EUS) that showed sessile polypoid lesion with overlying yellowish granular mucosa. Endosonographically, the lesion measured $10 \mathrm{~mm} * 7 \mathrm{~mm}$, was hypoechoic with a central calcification and appeared to arise from the mucosa and superficial submucosa corresponding to a granular cell tumor of the upper esophagus. No para-esophageal adenopathy noted. EMR was successfully done using methylene blue injection for a good elevation followed by snare mucosa resection with no complications. Pathology showed infiltrative tumoral proliferation composed of nests or trabeculae made up of large, round and oval cell having brightly eosinophilic granular cytoplasm. The cell borders are indistinct, and the nuclei are uniformly round and centrally situated. Pathology characteristics confirmed granular cell tumor (Figure 1). 

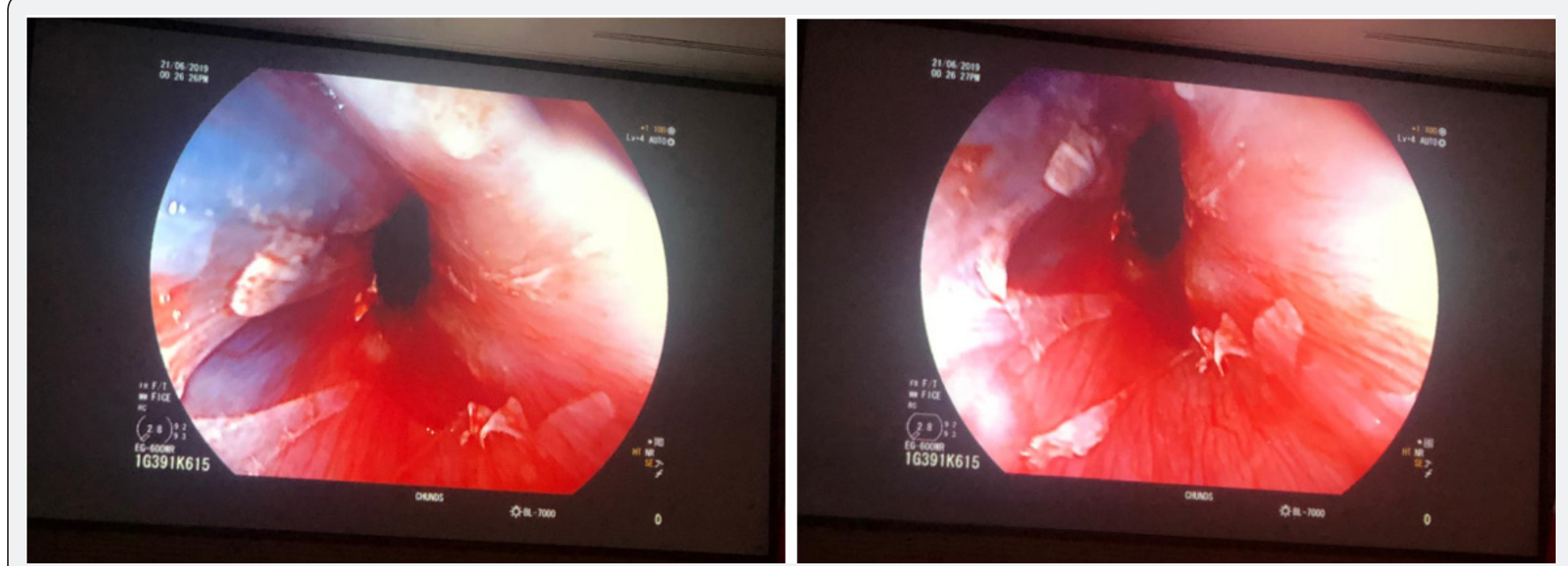

Figure 1: The Endoscopic picture After Removal of the Lesion.

\section{Discussion}

GCTs are rare tumors of GI tracts. Commonly they are found in the skin and subcutaneous tissues ( $70 \%$ of cases). $8 \%$ only of GCTs are found in GI tract, most of them are at the esophagus.1\% only of esophageal tumors are GCTs [1-5]. Abriksoosoff firstly described GCTs in 1926 [1]. Those tumors arise from Schwann cell which was proven based on immunohistochemical and ultrastructural findings [6]. Esophageal GCTs are more common in females, and in the age group between 40-60 years [5]. Their presence at younger age such as in our case in less commonly reported. Beside the uncommon age presentation, the location of the tumor contributes also to the uniqueness of the case. Most GCTs are found in the middle to distal esophagus. Goldblum et al. [7] reported that $92 \%$ of esophageal GCTs were located in the distal esophagus. Also, Wand \& Liu [8] found that $80 \%$ of cases are in the middle and distal esophagus. While small lesions are incidentally found during endoscopy, larger lesions $>1 \mathrm{~cm}$ presented with dysphagia and chest pain. It can mimic also typical symptoms of GERD. Endoscopically, GCTs appears as isolated, sessile, submucosal lesions that are yellow-white in color, firm, with a negative pillow sign [9]. They commonly arise from submucosa but can involve the mucosa or muscularis propria. EUS is essential in diagnosis by locating the origin of tumor precisely the layer from which it is arising and through fine needle aspiration (FNA). In addition, EUS can also contribute to the planning of the resection. They usually appear as hypoechoic and homogeneous lesions, with clear borders. Palazzo et al reported endoscopic features of 21 GCTs with the following characteristics: (1) tumor size $<2 \mathrm{~cm}$ in $95 \%$ of cases; (2) a hypoechoic solid pattern in all cases; and [3] a tumor arising in the inner layers in $95 \%$ of cases [10] (Figure 2).

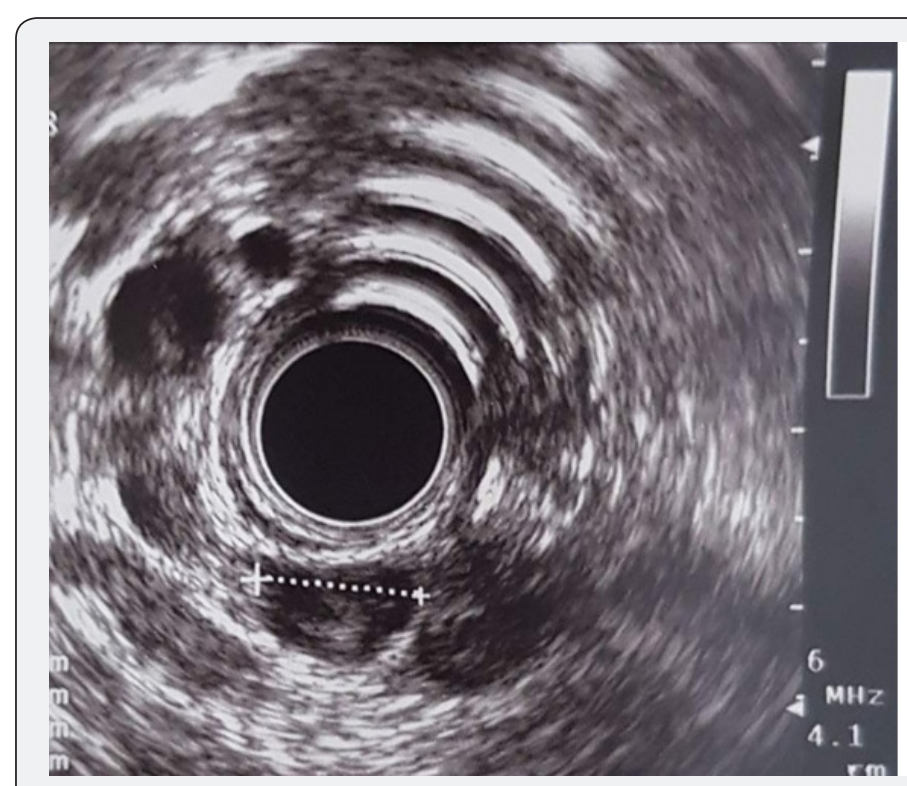

Figure 2: The EUS before removal of the lesion.

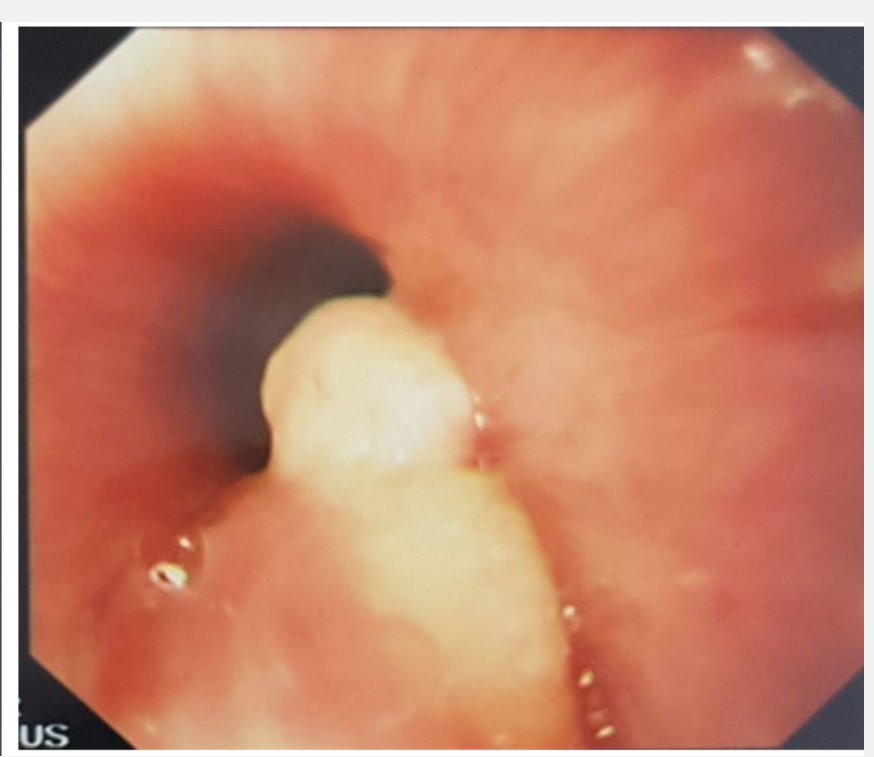

The Endoscopic Picture Before Removal of the 
The definitive diagnosis is made by histological examination. Histologic features are large polygonal cells with ill-defined borders, arranged in a nest or acinar form, that often contain eosinophilic granules with low nuclearcytoplasmic ratios. Immunohistochemistry will show tumor cells which would identify positive S-100, PAS, neuron-specific enolase and nestin. An et al. [11] demonstrated that almost all GCTs from GI tracts were labeled to S-100 protein (100\%), CD68 (95\%), CD56 (95\%), and SOX-10 (93\%). GCTs are benign tumors and malignancy is extremely rare. Fanburg-Smith et al. [12] described several criteria of malignancy, 3 at least should be met from the following: necrosis, spindling, vesicular nuclei with large nucleoli, increased mitotic activity a high nuclear-to-cytoplasmic ratio, and nuclear pleomorphism. Benign GCTs will be managed according to their size and depth. Asymptomatic tumors less than $1 \mathrm{~cm}$ can be conservatively approached with surveillance endoscopy. Larger tumors should be removed, by EMR tumors larger than $1 \mathrm{~cm}$, providing that they are not attached to muscularis propria. Endoscopic submucosal dissection (ESD) is also effective for larger and deeper tumor but with higher risks of bleeding and perforation. In cases of malignancy or tumors invading muscularis propria surgery should be considered with endoscopic surveillance postoperatively for malignant cases. In our case, the decision to resect the tumor was made, considering the symptoms of the patients, Successful EMR using methylene blue for good elevation followed by snare polypectomy was done without complications as seen in the figure

\section{Conclusion}

Esophageal GCTs should be considered when presenting with subepithelial lesions in the distal part of the esophagus in asymptomatic patients. EUS is the most beneficial diagnostic tool, which helps in planning appropriate treatment based on the depth of invasion. Complete endoscopic resection of esophageal GCTs either by EMR or ESD is recommended. Long- term endoscopic surveillance is always advised due to the high rate of recurrence.

\section{References}

1. Nie L, Xu G, Wu H, Huang Q, Sun Q et al. (2014) Granular cell tumor of the esophagus: a clinicopathological study of 31 cases. Int J Clin Exp Pathol 7(7): 4000-4007.

2. Nasser H, Ahmed Y, Szpunar SM, Kowalski PJ (2011) Malignant granular cell tumor: a look into the diagnostic criteria. Pathol Res Pract 207(3): 164-168.

3. Terada T (2009) Benign Tumors of the Esophagus: A Histopathologic Study of 49 Cases among 931 Consecutive Esophageal Biopsies. Gastroenterology Res 2(2):100-103.

4. Abrikossoff A (1926) Myomas originating from transversely striated voluntary musculature [Article in German]. Virchows Arch a Pathol Anat Histol 260: 215-233.

5. Sposto M, Navarro C, Roberto de Andrade C (2006) Granular cell tumour (Abrikossoff's tumour): case series. Oral Oncology Extra 42(5): 194-197.

6. Ordóñez NG, Mackay B (1999) Granular cell tumor: a review of the pathology and histogenesis. Ultrastruct Pathol 23(4): 207-222.

7. Goldblum JR, Rice TW, Zuccaro G, Richter JE (1996) Granular cell tumors of the esophagus: a clinical and pathologic study of 13 cases. Ann Thorac Surg 62(3): 860-865

8. Wang HQ Liu AJ (2015) Esophageal granular cell tumors: Case report and literature review. World J Gastrointest Oncol 7(8): 123-127.

9. Radaelli F, Minoli G (2009) Granular cell tumors of the gastrointestinal tract. Questions and answers. J Gastroenterol Hepatol 5(11): 798-800.

10. Palazzo L, Landi B, Cellier C, Roseau G, Chaussade S, et al. (1997) Endosonographic features of esophageal granular cell tumors. Endoscopy 29(9): 850-853.

11. An S, Jang J, Min K, Kim MS, Park H, et al. (2015) Granular cell tumor of the gastrointestinal tract: histologic and immunohistochemical analysis of 98 cases. Hum Pathol 46(6): 813-881.

12. Fanburg-Smith JC, Meis-Kindblom JM, Fante R, Kindblom LG (1998) Malignant granular cell tumor of soft tissue: diagnostic criteria and clinicopathologic correlation. Am J Surg Pathol 22(7): 779-794. 